\title{
Dossiê
}

\begin{abstract}
Resumo
Este trabalho tem como ponto de partida os enigmas suscitados pelo discurso de duas pacientes para refletir sobre as dores do parto e o pathos nele implicado. $O$ trabalho visa aprofundar a dimensão dolorosa do nascimento, posto que nele opera um processo de disjunção. Analisa-se como a dor e o sofrimento vivenciados por Tânia e Luíza no momento do parto configuram a angústia atrelada ao inquietante $e$ ao narcisismo primitivo. O texto também ressalta a "lavagem das dores" como possibilidade terapêutica, a qual viabiliza a passagem da angústia provocada pela disjunção para a emergência do amor materno.
\end{abstract}

Descritores: dores do parto; disjunção; angústia; narcisismo primitivo; amor materno.

\section{AS DORES DO PARTO. REFLEXÕES PSICOPATOLÓGICAS EM TORNO DA ANGÚSTIA E DO NARCISISMO PRIMITIVO}

\author{
Vívian Anijar Fragoso Rei \\ Xochiquetzaly Yeruti de Avila Ramírez \\ Manoel Tosta Berlinck
}

DOI: http://dx.doi.ors/10.11606/issn. 1981-1624.v19i1p67-77

Oh, pedaço de mim

Oh, metade arrancada de mim

Leva o vulto teu

Que a saudade é o revés de um parto

(Chico Buarque de Holanda)

\section{As dores do parto}

Em certo atendimento, Tânia ${ }^{1}$ narra a situação do nascimento de sua filha. Logo quando sentiu as primeiras contrações, a pacien-

Psicóloga, doutoranda em Psicologia Clínica e pesquisadora membro do Laboratório de Psicopatologia Fundamental da Pontifícia Universidade Católica de São Paulo (PUC-SP). Bolsista do Conselho Nacional de Desenvolvimento Científico e Tecnológico (CNPq), São Paulo, SP, Brasil.

- Doutoranda em Psicologia Clínica e pesquisadora do Laboratório de Psicopatologia Fundamental da Pontifícia Universidade Católica de São Paulo (PUC-SP). Bolsista do Programa Estudantes-Convênio de Pós-Graduação do Conselho Nacional de Desenvolvimento Científico e Tecnológico (CNPq),

São Paulo, SP, Brasil.

- - - Professor da Faculdade de Ciências Humanas e da Saúde e do Programa de Pós-graduação em Psicologia Clínica da Pontifícia Universidade Católica de São Paulo (PUC-SP), São Paulo, SP, Brasil. 
te lembra que procurou alguém que pudesse acompanhá-la para o hospital, mas não encontrou. Decidiu ir sozinha.

Tânia relata que começou a sentir dores do parto e se direcionou ao hospital. Lá chegando, a paciente foi encaminhada para uma sala de pré-parto. Naquele local, as dores foram se intensificando, uma vez que o momento de dar a luz se aproximava.

Esperando ter a dilatação necessária para que a criança pudesse nascer, Tânia permaneceu algumas horas sozinha na referida sala, e foi visitada esporadicamente por uma enfermeira que conferia as condições da paciente. Quando o bebê deu sinais de que viria ao mundo, médicos e enfermeiros se aproximaram de Tânia e a auxiliaram a dar a luz.

Tânia relata que, mesmo após o nascimento da filha, as dores permaneciam em seu corpo e sentia como se fosse morrer. Ela lembra que nem conseguiu pegar a criança no colo e sua única reação foi um choro intenso e incessante. Ao recordar, a paciente diz nunca ter sentido sensação tão dolorosa. As dores foram relatadas como não localizáveis em nenhuma parte do corpo, sendo tomada por uma sensação "aterrorizadora de vazio".

Após ficar muito tempo nessa situação, uma enfermeira entrou na sala e disse que precisava dar um banho em Tânia. Enquanto a enfermeira lavava seu corpo, a paciente relatou que sentia como se as dores fossem diluídas com a água. Nas palavras de Tânia, "as dores foram lavadas".

A paciente recordou que a enfermeira não somente tocava seu corpo, mas conversava com ela, dizendo que tudo aquilo iria passar. Percebe-se que esta profissional efetuava uma espécie de consolo à paciente, diante da dor que acabara de sentir.

Quando finalizou o banho, a enfermeira perguntou se a paciente queria pegar a criança no colo e, somente após ser banhada, Tânia conseguiu olhar para a filha, que se encontrava em um berço ao lado da cama.

Tânia conseguiu, então, olhar com amor para sua filha e se dedicar ao cuidado dela, pegando-a em seus braços e amamentando-a.

Esta angústia sentida no momento pós-parto também foi relatada por Luíza. A paciente relatou que enquanto ainda se encontrava na sala de parto, foi tomada por um forte aperto no peito e uma sensação de extrema angústia. Ela recorda que, logo após o parto, só conseguia pensar não se sentir capaz de cuidar daquele pequeno ser que acabara de vir ao mundo. 
Reflexões sobre a disjunção no parir

O que emerge como enigma nessas situações narradas é o sentimento de extrema angústia que acometeu essas mulheres após o parto de suas filhas. A angústia é descrita por Freud (1933/2010a) como um estado afetivo oriundo da "união de determinadas sensações da serie prazer-desprazer" (p. 224).

Freud ainda acrescenta que se trata provavelmente de "o precipitado de certo evento significativo, incorporado por hereditariedade" (p. 224). O autor sugere, também, que "o evento que deixa um traço afetivo desses é o nascimento" (Freud, 1933/2010a, p. 225).

Destaca-se que o momento do nascimento de uma criança é denominado na língua portuguesa pelo vocábulo "parto", palavra que também é utilizada na conjugação do presente do indicativo do verbo partir.

Para a mãe, a vivência do nascimento do filho é uma "partida", talvez por isso, a dor do parto é comumente denominada como uma das mais intensas dores vivenciadas pelo humano, pois nela estão implicados a angústia e demais afetos relativos a uma mudança interna e à atualização de uma perda.

Com base em uma concepção econômica, Catão (2011) define a dor como um excesso de excitação a qual invade os dispositivos protetores e “está ligada a uma ruptura, um extravasamento desorganizador, desestruturante da economia psíquica” (p. 80).

Vale ressaltar que o verbo "partir" é utilizado tanto para marcar o deslocamento no espaço (ex.: Eu parto para São Paulo), como também para dividir algo em partes (ex.: Eu parto o pão em duas partes). $\mathrm{O}$ momento do parto tem estas duas dimensões: deslocamento do ventre para o mundo e disjunção ${ }^{2}$ da unidade mãe-bebê.

Sobre a disjunção, retoma-se a noção de separação elaborada por Lacan. Para o autor, a separação é proposta como a segunda operação essencial a qual fundamenta o sujeito. A operação da separação, para Lacan (1998), é representada pela interseção de elementos que pertencem aos dois conjuntos (o ser e o sujeito). Nesse sentido, a separação está fundamentada na interseção ou produto entre o sujeito e o Outro.

A separação marca a tentativa de saída do lugar de objeto, assumindo, assim, a condição de sujeito desejante e, portanto, faltoso. A operação de separação inicia quando o Outro (encarnado na figura materna) evidencia um sinal de sua incompletude. Logo, o ser em constituição, reconhece a sua impossibilidade em tamponar a falta do outro e, com isso, percebe a própria falta.

Lacan (1998), para fundamentar a operação de separação, recorre à etimologia desta palavra. Em latim, o termo engendrar é referido a "pôr no mundo". 
aí está a origem da palavra que designa em latim o engendrar. Ela é jurídica, como, aliás, coisa curiosa, em indo-europeu, todas as palavras que designam "pôr no mundo". A própria palavra parturição se origina-se numa palavra que, em sua raiz, não quer dizer outra coisa senáo procurar um filho para o marido, operação jurídica, e, digamos logo, social. (Lacan,1998, pp. 202-203, itálico do autor)

Desse modo, está implícito na separação este "pôr no mundo", o qual, acredita-se, é iniciado com o parto.

Verifica-se assim que no momento da partição - no duplo sentido aqui atribuído - prevalece uma forma de ausência de "preparação para a angústia” (Freud, 1920/2010b, p. 195), em que "os sistemas não se acham em boas condições de ligar as quantidades de excitação que chegam, e as consequências da ruptura da proteção se verificam mais facilmente" (Freud, 1920/2010b, p. 195).

A parturição ${ }^{3}$, além de ser o momento de dar a luz, é também, como descreve Zaltzman (1978, p. 23, citado por Pinheiro, 1991, p. 132), uma "fascinação horrorosa", pois não somente atrela o fascínio enigmático do nascimento, como também envolve "o momento particular em que uma criança começa a emergir das pregas da carne materna".

Destaca-se com isso que, além do fascínio, no momento do parto, a mãe é atravessada por uma angústia, evidência da intensa dor que marca o processo de disjunção.
A parturição implica a coexistência de desprendimento e expulsão, fenômenos de disjunção vivenciados no corpo, onde este é partido e atravessado por uma dor indeterminada à beira do insuportável.

O que é esse quase insuportável que produz essa disjunção na ocasião do parto? Segundo Pinheiro (1991), o poder de gerar vida dentro de si mesma, essa plenitude de ser dois num só corpo é, sem dúvida, para a mulher, o ápice de sua vivência narcísica.

Mas essa plenitude e esse prazer nem sempre são constantes. No parto há uma irrupção violenta, a presença de uma força intensificada que gera, além das dores físicas do parir, a angustiante perda. Em tal perda, cujo alicerce é o inquietante, a mulher "co-nasce" ao dar a luz. Além do seu nascimento enquanto mãe, pode-se afirmar, também, que a mulher, ao parir, faz renascer angústias e afetos, marcas da vivência primitiva de disjunção.

O que ou qual é essa força que produz uma vivência dolorosa para a mãe? A disjunção é presença e força de desinvestimento, não constitui destruição, mas oposição à função de ligação, ou seja, algo que emerge no momento do parto como angústia de desligamento.

A perda vivenciada no parto é relacionada à lembrança de uma disjunção arcaica, rememoração de desligamento primitivo e originário. Entende-se que as intensas dores e a inquietante angústia, suscitadas no 
momento do parto, segundo os relatos de Tânia e Luíza, configuramse nas camadas dessa perda.

Essa completude refere-se à revivescência de um momento infantil permeado pela sensação de eternidade, de algo ilimitado e sem barreiras, como se fosse oceânico (Freud, 1930/2010c). Ocorre que, tal como afirmado por Freud na discussão efetuada posteriormente à conferência proferida por Hilferding (1991), "o efeito principal que produz a visão da criança é o de fazer renascer a sexualidade infantil da mãe" (p. 95).

Desde antes da concepção, o bebê é gestado psiquicamente, e esta gestação é fundamentada no ideal transmitido e herdado ao longo das gerações. A afirmação precedente atrela-se ao que, num aprofundamento do conceito de "contrato narcisístico" de Piera Aulagnier, (Aulagnier, 1975 citada por Monti, 2008) afirma que a reativação do narcisismo parental é o vínculo que garante a continuidade entre as gerações. Sobre isso, Freud afirma que

A criança deve satisfazer os sonhos e os desejos nunca realizados dos pais ... o comovente amor parental, no fundo tão infantil, não é outra coisa senão o narcisismo renascido dos pais, que, ao se transformar em amor objetal, acaba por revelar inequivocamente sua antiga natureza. (Freud, 1914/2004, p. 110)

Nesse momento, o narcisismo primitivo poderia ser pensado como um espaço-tempo reanimado pela perda intensamente revivenciada no momento do parto, em que governa inominável dor e infranqueável angústia.

Essa questão é esclarecida por Berlinck (2008) ao afirmar que o narcisismo primitivo ocorre diretamente no corpo sem uma intermediação psíquica e, se por um lado, contribui decisivamente para a evolução do psiquismo, por outro, produz angústia.

Nessa tentativa de análise da noção de narcisismo primitivo, Berlinck (2008) define-o como imaginário inconsciente dos antepassados. Entende-se que esta definição abrange uma topologia e uma dinâmica.

O elemento topológico encontra-se na qualidade imaginária do primitivo, ou seja, na configuração da forma e posição inconsciente do corpo, em uma série de lugar, posição e figura. A dinâmica envolve um movimento de retorno determinado pelo que é transmitido transgeracionalmente.

Nesse sentido, García-Roza, ao se referir à noção de Real-Ich, define-o como um 
estado originário do psiquismo no qual ainda não há distinção entre o eu e o mundo exterior, e tampouco a oposição prazer-desprazer, pois no Real-Ich o eu satisfaz as pulsões em si mesmo. (García-Roza, 1990, p. 91)

Deste modo, reconhece-se a aproximação entre o Real-Ich citado por García-Roza (1990) e a noção de narcisismo primitivo que atestam a ideia de uma preexistência e de um estado de indiferenciação. Freud (1919/2010d) esboçou essa forma mítica ao apontar para a preexistência de "um tempo em que o Eu ainda não se delimitava nitidamente em relação ao mundo externo e aos outros" (p. 354).

Assim, o momento do parto introduz, para a mãe, uma desordem no fluxo pulsional e libidinal, pois aparece como irrupção da ordem psíquica, não somente pela dor, angústia e perda, mas pelos movimentos regressivos que abrangem a revivescência do narcisismo primitivo, o qual se configura como condição onde surgem as primeiras tentativas de organização psíquica.

Freud afirma que "o elemento angustiante é algo reprimido que retorna” (1919/2010d, p. 360). Nesse sentido, a angústia relatada por estas mães, é relacionada ao que retorna da vivência arcaica de perda e seu consequente desamparo.

A vivência angustiante da perda é abordada por Souza (2005) ao afirmar que

a angústia emerge nos momentos de separação, corte ou perda, momentos que comemoram a perda primeira - localizada no Outro e, ao mesmo tempo, no sujeito que se situa aí - e que póem em jogo a própria perda do sujeito. A angústia aparece nos momentos em que o sujeito é obrigado a ceder - ceder algo precioso, algo que ele preferiria reter, algo cuja perda lhe ameaça de queda, desmoronamento, morte. (Souza, pp. 18-19)

Pode-se identificar o atrelamento entre angústia e narcisismo primitivo, simultaneidade a qual permite inferir a presença de algo Unheimliche que retorna no momento do parto.

Freud (1919/2010d) conclui que "o inquietante é aquela espécie de coisa assustadora que remonta ao que é há muito conhecido, ao bastante familiar" (p. 331). Nos casos citados neste trabalho, o que retorna é o traço permanente do narcisismo primitivo, angústia inaugural que traz a marca da inserção do homem no mundo.

Por causa disso, torna-se necessário lavar o corpo das marcas da partida, ou seja, é necessário, além do trabalho de parir, um trabalho de "lavagem das dores" do parto (do parir e do partir). Uma elabo- 
ração que possibilite suturar a ferida da disjunção, uma operação psíquica que, em princípio, requer uma lavagem das dores para, posteriormente, potencializar a capacidade de amar.

\section{A lavagem das dores: caminhos da therapeía}

Identifica-se que a angústia sentida no momento do parto é vivenciada como uma irrupção que atravessa o psíquico, provocada pela intensidade de uma perda a qual revela a fragilidade do humano.

Na vivência dolorosa, como exemplificado por Rinaldi (2011), o corpo só se torna "ser" pelas palavras que o recortam. Tornar-se ser pela via da "lavagem das dores" é uma interpelação, função que, segundo Figueiredo (2007, envolve o seduzir e o reclamar como condições para um corpo asceder à vida e à humanidade.

A "lavagem das dores" é considerada, neste trabalho, como processo de reparação, pois permite à mulher que acaba de dar a luz restaurar a condição sexuada do corpo. Tal processo é um trabalho em que o corpo é banhado por eros, resgatando-o da ameaça provocada pela disjunção ocorrida no momento do parto.

A "lavagem das dores", belamente relatada por Tânia, é considerada uma lavagem psíquica. Em outras palavras, é uma operação promovida por um agente de cuidado que fornece, de certo modo, a terapêutica da restituição. Os cuidados fornecidos pela enfermeira que toca e lava o corpo da paciente possibilita restituir o eros, lacerado pela partida.

Diante da perda, a "lavagem das dores" opera como um consolo, o qual porta uma possibilidade terapêutica. Essa função de consolação é aprofundada por Carvalho da Silva (2007), o qual assinala que antigamente "o emprego do discurso, em um diálogo, a fim de ensinar a superação racional das paixões tristes e dores da alma se chamava consolação" (p. 147). Nesse sentido, consolar é oferecer possibilidade de restituição, novas ligações.

Fédida (1988) retoma a tradição platônica e afirma que

therapeía em grego é o cuidado exercido sobre o eros doente. O médico deve restabelecer o equilíbrio do corpo para que o eros doente pelo excesso de amor seja liberado desse excesso pelo amor que lhe traz o médico. (Fédida, 1988, p. 28, itálico do autor) 
Já Freud (1907/1996a, p. 82) afirma que "O processo de cura é realizado numa reincidência no amor ... Todo tratamento psicanalítico é uma tentativa de libertar o amor reprimido". Retomando o caso, uma forma de cura, no sentido de libertar o amor reprimido, aparece como uma possibilidade terapêutica oferecida pelo contato físico que "lava" o excesso.

'terapéia' significa algo peculiar: desde que nos ocupemos do ser humano, tudo o que se passa entre ele e nós, nos mínimos detalhes, reveste uma significação de fragilidade. Exatamente o que implica o termo 'terapéia'; em 'terapéia' há uma cono'tação de respeito pela divindade. Eu diria que é a atenção delicada dada ao homem como se fosse um instrumento musical. Em função da posição que ocupamos, cada coisa que dizemos ou fazemos tem imediatamente uma incidência sobre a matéria vivente que o homem doente nos oferece. (Fédida, 1988, pp. 30-31)

Deste modo, o princípio que opera na terapeia é o restabelecimento do corpo, em que ele pode ser liberado do excesso e reencontrar a harmônica, a qual possibilita o equilíbrio de eros.

Nesse sentido, para que o pathos se torne uma psicopatologia, isto é, "um sofrimento que porta em si mesmo a possibilidade de um ensinamento interno" (Fédida, 1988, p. 29), é imprescindível a presença do outro, no lugar de estrangeiro, que possa cuidar do sofrimento.

A enfermeira que lava o corpo de Tânia ocupa o lugar terapêutico do estrangeiro, posição a qual requer o 
debruçar-se sobre o corpo dolorido da paciente. Ao tocar o corpo, há um acolhimento da dor, promovendo o contato necessário para o apaziguamento da angústia, pois somente assim será possível a emergência do amor materno.

A afirmação precedente é também considerada por García-Roza (1990) ao apontar que o corpo, não sendo autossuficiente, necessita de algo externo a ele, outro corpo, para se manter vivo. Assim, a função terapêutica de "lavagem das dores" investe de erotismo o corpo da mãe para, posteriormente, subjetivar o corpo do bebê no atrelamento a uma cadeia erotizante.

Posteriormente a vivência de disjunção, a função terapêutica da lavagem das dores, constitui-se como a transmissão de uma experiência de integração (Figueiredo, 2007) exercida, ensinada e facilitada pela via do cuidado.

Tal ação de "lavagem das dores" opera como via que pode oferecer condições e possibilidades para que uma experiência de transformação apareça. Capacidade que visa a transmissão do cuidar de si, a multiplicação de laços e a diferenciação do próprio e do alheio, ou seja, tecer um envelope erótico que dá ao corpo um contorno, permitindo assim a alteridade e a emergência do amor materno.

A "lavagem das dores" opera como uma função de circunscrição do corpo, contato físico que faz limite diante da ameaça de desbordo da ultrapassagem dos limites da dor e da angústia. Eis que a "lavagem das dores", demarcada pela presença de outro que toca, lava e fala, opera como ativador do amor materno transmitido ao longo das gerações.

Ao refletir sobre o encontro com o outro maternal, Fernandes (2003) aponta que a presença desse outro é vital, sendo parte intrínseca e necessária da constituição do aparelho psíquico.

O banho promove a ativação do cuidado vivenciado em um momento anterior, possibilitando o resgate do narcisismo primitivo, transmitido ao longo das gerações. Portanto, essa lavagem referida por Tânia é uma rememoração de um vestígio maternal que sustenta o surgimento do amor da paciente pela sua filha.

\section{Considerações finais}

Atreladas ao narcisismo primitivo e à angústia, nas dores do parto estão implicados dois processos: disjunção e retorno ao primitivo. A disjunção configura-se pela separação e perda, a qual reativa um vestígio do narcisismo primitivo, em que há a prevalência de um excesso expresso pela hipersensibilização corporal. 
Diante da intensidade dolorosa, um caminho terapêutico se configura na "lavagem das dores", a qual possibilita a restituição do envelope narcísico e favorece a emergência do amor materno.

Assim, o amor materno é atravessado pela dor, e a dor circunda infalível o amor. Dor e amor são, portanto, aliados.

THE PAINS OF CHILDBIRTH. PSYCHOPATHOLOGICAL REFLECTIONS AROUND ANXIETY AND PRIMITIVE NARCISSISM

\begin{abstract}
This work has as starting point the enigmas raised by the speech of two patients in order to reflect about the pain of childbirth and the pathos involved in it. The paper seeks to deepen the painful dimension of childbirth, as it operates a process of disjunction. It analyzes how the pain experienced by Tânia and Luiza at the time of childbirth configures the anxiety related with the uncanny and the primitive narcissism. The text also highlights the "washing of the pains" as a therapentic option that eases the passage of the anxiety caused by the disjunction towards the emergence of maternal love.
\end{abstract}

Index terms: pains of childbirth; disjunction; anxiety; primitive narcissism; maternal love.

LOS DOLORES DEL PARTO. REFLEXIONES PSICOPATOLÓGICAS EN TORNO DE LA ANGUSTLA Y DEL NARCISISMO PRIMITIVO.

\section{REsumen}

Este trabajo tiene como punto de partida los enigmas suscitados por el discurso de dos pacientes para reflexionar en torno de los dolores del parto y el "pathos" en el implicado. El trabajo busca profundizar en la dimensión dolorosa del nacimiento puesto que en este opera un proceso de disyunción. Se analiza como el dolor vivenciado por Tânia e Luiza en el momento del parto configura la angustia relacionada con lo inquietante y el narcisismo primitivo. El texto también resalta la "limpieza de los dolores" como posibilidad terapéutica que viabiliza el pasaje de la angustia provocada por la disyunción hacia la emergencia del amor materno.

Palabras clave: dolores de parto; disyunción; angustia; narcisismo primitivo; amor materno.

\section{REFERÊNCIAS}

Berlinck, M. T. (2008). Psicopatologia fundamental. São Paulo: Escuta.

Catão, P. L. (2011). Sublima-dor. Considerações sobre dor e sublimação nos limites do pulsional. Reverso, 33 (62), 79-84.

Carvalho da Silva, P. J. (2007). O ideal da consolação e a paixão pela morte. Revista Latinoamericana de Psicopatologia Fundamental, 10 (1), 146-154.

Fédida, P. (1988). Clinica psicanalítica: estudos. São Paulo: Escuta.

Fernandes, M. H. (2003). Corpo. São Paulo: Casa do Psicólogo.

Figueiredo, L. (2007). A metapsicologia do cuidado. Psychê, 11 (21), 13-30.

Freud, S. (1996a). Delírios e sonhos na Gradiva de Jensen. In S. Freud, Edição standard brasileira das obras psicológicas completas de Sigmund Freud. 'Gradiva' de Jensen e outros trabalhos. (J. Salomão, trad., Vol. 9, pp. 15-88). Rio de Janeiro: Imago. (Trabalho original publicado em 1907)

Freud, S. (1996b). O eu e o id. In S. Freud, Obras completas. O eu e o id, "Autobiografia" e outros textos. (P. C. Souza, trad., Vol. 16, pp. 13-74). São Paulo: Companhia das Letras. (Trabalho original publicado em 1923)

Freud, S. (2004). À guisa de introdução ao narcisismo. In S. Freud, Obras psicológicas de Sigmund Freud. Escritos sobre a psicologia do inconsciente. (Vol. 1, pp. 95-131). Rio de Janeiro: Imago. (Trabalho original publicado em 1914)

Freud, S. (2010a). Novas conferências introdutórias à psicanálise. In S. Freud, Obras completas. O mal-estar na civilização, novas 
conferencias introdutórias à psicanálise e outros textos (P. C. Souza, trad., Vol. 18, pp. 224-262). São Paulo: Companhia das Letras. (Trabalho original publicado em 1933)

Freud, S. (2010b). Além do princípio do prazer. In S. Freud, Obras completas. História de uma neurose infantil: ("O homem dos lobos"), além do principio do prazer e outros textos. (P. C. Souza, trad., Vol. 14, pp. 161-239). São Paulo: Companhia das Letras. (Trabalho original publicado em 1920)

Freud, S. (2010c). O mal-estar na civilização. In S. Freud, Obras completas. O mal-estar na civilização, novas conferencias introdutórias à psicanálise e outros textos. (P. C. Souza, trad., Vol. 18, pp. 13-122). São Paulo: Companhia das Letras. (Trabalho original publicado em 1930)

Freud, S. (2010d). O inquietante. In S. Freud, Obras completas. História de uma neurose infantil: ("O homem dos lobos"), além do princípio do prazer e outros textos. (P. C. Souza, trad., Vol. 14, pp. 328-376). São Paulo: Companhia das Letras. (Trabalho original publicado em 1919)

García-Roza, L. (1990). O mal radical em Freud. Rio de Janeiro: Jorge Zahar.

Hilferding, M. (1991). Reunião de 11 de janeiro de 1911. Ata da Sociedade Psicanalítica de Viena. In M. Hilferding, T. Pinheiro \& H. B. Vianna, As bases do amor materno (T. Vianna, trad., pp.85-101). São Paulo: Escuta.

Lacan, J. (1998). O seminário, livro 11: os quatro conceitos fundamentais da psicanálise, 1964. Rio de Janeiro: Jorge Zahar.

Monti, M. R. (2008). Contrato narcisista e clínica do vazio. Revista Latinoamericana de Psicopatologia Fundamental, 11 (2), 239-253.

Pinheiro, T. (1991). Reflexôes sobre as bases do amor materno. In M. Hilferding, T. Pinheiro \& H. B. Vianna, As bases do amor materno (pp. 103-134). São Paulo: Escuta.
Rinaldi, D. (2011). O corpo estranho. Revista Latinoamericana de Psicopatologia Fundamental, 14 (3), 440-451.

Souza, N. S. (2005). A angústia na experiência analítica. In M. S. G. F. Hanna \& N. S. Souza (Orgs.), O objeto da angústia. (pp. 15-31). Rio de Janeiro: 7Letras.

\section{NOTAS}

1. Os nomes das pacientes citadas no presente estudo foram alterados a fim de preservar suas identidades.

2. Neste trabalho o termo disjunção é empregado para se referir ao momento de separação entre o corpo da mãe e o do bebê. Tal termo encontra-se referido no ensaio "O eu e o id", em que Freud (1923/1996b) emprega-o no sentido de um desligamento pulsional. $\mathrm{O}$ autor afirma que ao haver uma mescla, impóe-se a possibilidade de uma disjunção.

3. Nome empregado para se referir ao momento do parto.

4. Unheimliche é o termo alemão utilizado por Freud (1919/2010d) para se referir ao que Paulo César de Souza traduziu como "O inquietante".

vivianrei@hotmail.com Rua Afonso de Freitas, 66/102 04006-050 - São Paulo - SP - Brasil.

xoyeruti@gmail.com Rua Baronesa de Itu, 64/11 01231-000 - São Paulo - SP - Brasil.

mtberlin@uol.com.br

Rua Tupi, 397/103

01233-001 - São Paulo - SP - Brasil.

Recebido em maio/ 2013. Aceito em fevereiro/ 2014. 